Article

\title{
High-Frequency Fatigue Testing of Recycled Aggregate Concrete
}

\author{
Jose Sainz-Aja, Carlos Thomas * , Juan A. Polanco and Isidro Carrascal \\ LADICIM (Laboratory of Materials Science and Engineering), University of Cantabria, \\ E.T.S. de Ingenieros de Caminos, Canales y Puertos, Av./Los Castros 44, 39005 Santander, Spain; \\ jose.sainz-aja@unican.es (J.S.-A.); polancoa@unican.es (J.A.P.); carrasci@unican.es (I.C.) \\ * Correspondence: carlos.thomas@unican.es
}

Received: 11 November 2019; Accepted: 11 December 2019; Published: 18 December 2019

\begin{abstract}
Concrete fatigue behaviour has not been extensively studied, in part because of the difficulty and cost. Some concrete elements subjected to this type of load include the railway superstructure of sleepers or slab track, bridges for both road and rail traffic and the foundations of wind turbine towers or offshore structures. In order to address fatigue problems, a methodology was proposed that reduces the lengthy testing time and high cost by increasing the test frequency up to the resonance frequency of the set formed by the specimen and the test machine. After comparing this test method with conventional frequency tests, it was found that tests performed at a high frequency $(90 \pm 5 \mathrm{~Hz})$ were more conservative than those performed at a moderate frequency $(10 \mathrm{~Hz})$; this effect was magnified in those concretes with recycled aggregates coming from crushed concrete (RC-S). In addition, it was found that the resonance frequency of the specimen-test machine set was a parameter capable of identifying whether the specimen was close to failure.
\end{abstract}

Keywords: high-frequency fatigue test; recycled aggregate; recycled aggregate concrete; fatigue; Locati test

\section{Introduction}

Recycled aggregates have an environmental benefit [1,2] and recycling is a necessity as the rate of waste generation is such that landfills are close to saturation [3]. Additionally, the possibility of obtaining recycled concrete (RAC) with good mechanical [4] and durability [5] properties has been proven. The ability of these recycled aggregates for use in self-compacting concrete [6], even with fine recycled aggregates [7], has also been proven. Even Kareem et al. [8] have used RAC for the manufacture of hot-mix asphalt.

Concrete fatigue behaviour has not been extensively studied, partly because of the difficulty, cost and time required. Concrete elements subjected to this type of load include railway superstructures, sleepers or slab tracks [9], rail and road bridges [10], offshore structures subject to variable wind and tidal loads [10,11] and/or wind generators [12]. Khosravani et al. [13] have defined a procedure for analyzing ultra-high performance concrete's response to impacts. As Skarżyński et al. state, knowledge about the effect of cyclic loads on concrete is currently very limited [12]. Several authors have analysed the responses of concrete. Xiao et al. [11] analysed the behavior of RAC to both compression and bending fatigue. $\mathrm{Li}$ et al. [14] analysed the influence of compressive fatigue on a fiber-reinforced cementitious material. Thomas et al. analysed the concrete fatigue behavior using two different methods: the staircase method [15] and the Locati method [16]. Innovative techniques, such as micro computed tomography (micro-CT) have also been used to analyze the behavior of concrete at fatigue, both in compressive fatigue [12] and bending fatigue [17]. Moreover, some micro-CT studies, which is a technique able to analyse the pores and cracks on concrete [18,19], had been developed to 
understand the concrete damage fatigue micromechanism [20,21]. In general, fatigue is known to lead to microcracks in concrete growing at lower loads than in static tests, which can lead to concrete failure earlier than expected [22].

It is well known that the fatigue limit of concrete depends on different factors. At higher stresses, the fatigue strength decreases with decreasing frequency $[12,23,24]$. The fatigue strength is also affected by the water/cement ratio, cement content, concrete type, rest periods, curing conditions and age during loading [25]. It is assumed that damage linearly increases with the number of cycles applied at a certain stress level [24]. The strain at the concrete failure during fatigue tests approximately corresponds to that at the peak load during quasi-static tests [26]. The failure meso-mechanism in concrete under fatigue compressive tests is almost the same as in monotonic compressive tests [27].

In order to reduce the characterization time as much as possible, the influence of increasing the test frequency up to the resonance frequency of the set of specimens and test machine [28] has been analyzed. In response to this proposal, several authors $[23,29,30]$ indicate that the range of frequencies to be tested should be between 1 and $15 \mathrm{~Hz}$, since they state that within this range, the effect of frequency is limited. It is justifiable to set the minimum at $1 \mathrm{~Hz}$ in order to avoid an excessive increase in the effect of creep in very long duration tests. However, there is no justification for setting the maximum at $15 \mathrm{~Hz}$.

Fatigue tests are proposed for classification according to the frequency of the test, distinguishing between low frequency tests, moderate frequency tests and high frequency tests. Low frequency tests are carried out at less than $1 \mathrm{~Hz}$, moderate frequency tests between 1 and $15 \mathrm{~Hz}$ and high frequency tests at more than $15 \mathrm{~Hz}$.

Three types of recycled self-compacting concrete were characterized in this investigation of compression fatigue tests. This characterization was developed both at a moderate frequency $(10 \mathrm{~Hz})$ and a high frequency $(90 \mathrm{~Hz})$. First, the results of the Locati tests were compared with $2 \times 10^{5}$ cycles per step at moderate and high frequencies, where it was possible to show that the tests carried out at a high frequency were notably more conservative than those at a moderate frequency. Second, the influence of the number of cycles per step in the high frequency Locati tests was analysed, where similar results were obtained using both test methodologies.

\section{Materials and Methods}

\subsection{Aggregates}

Recycled aggregates used for the manufacture of concretes were obtained from the crushing of ballast (RA-B) and out-of-use sleepers (RA-S). After crushing these materials, three granulometric fractions were obtained from each of these wastes (see Table 1). The grading of the six fractions of the two crushed products can be seen in Figure 1. Additionally, Table 1 shows the results of the relative density of the coarse aggregate and the real densities of the sands. The flakiness index of the two coarse aggregates was also determined, obtaining a value of $14 \%$ for RA-B-CA and $5 \%$ for RA-S-CA.

Table 1. Aggregate properties.

\begin{tabular}{|c|c|c|c|}
\hline Code & Description & Min.-Max. Size (mm) & Density $\left(\mathrm{g} / \mathrm{cm}^{3}\right)$ \\
\hline RA-B-CA & Ballast coarse aggregates & $5-12$ & 2.5 \\
\hline RA-S-CA & Sleeper coarse aggregate & $5-12$ & 2.3 \\
\hline RA-B-LS & Ballast coarse sand & $2-5$ & 2.7 \\
\hline RA-S-LS & Sleeper coarse sand & $2-5$ & 2.4 \\
\hline RA-B-FS & Ballast fine sand & $0-2$ & 2.8 \\
\hline RA-S-FS & Sleeper fine sand & $0-2$ & 2.5 \\
\hline
\end{tabular}




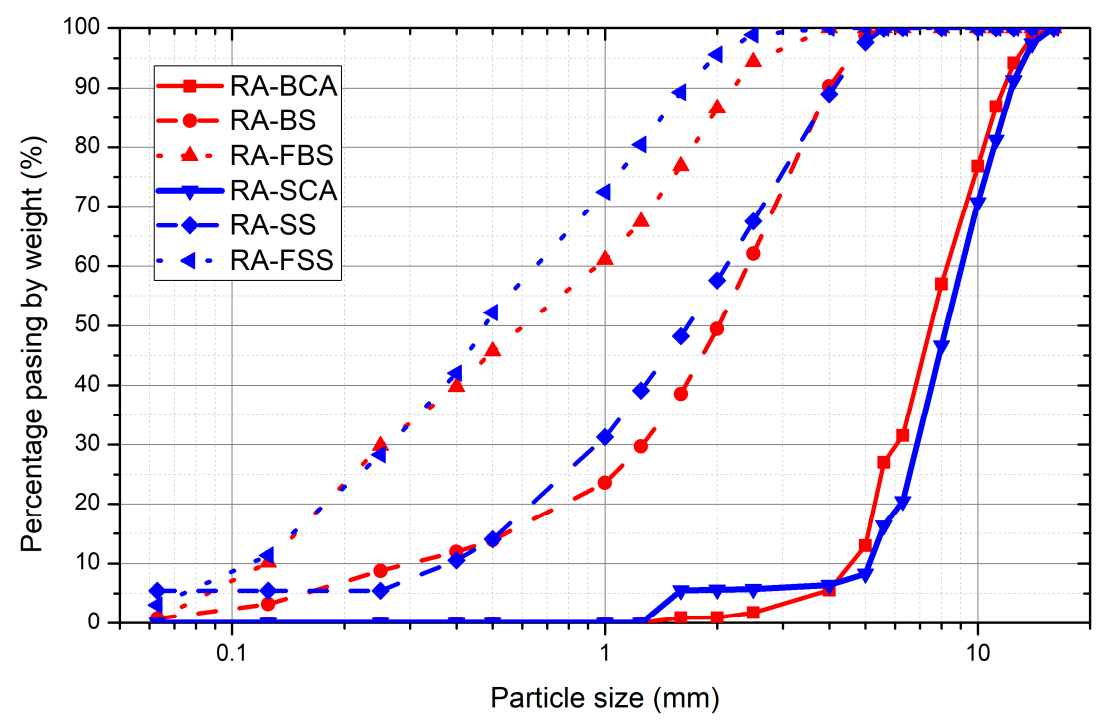

Figure 1. Aggregate grading curves.

\subsection{Cement}

A CEM IV (V) $32.5 \mathrm{~N}$ type cement according to EN 197-1 [31] was used, provided by Alpha cements [32], with a density of $2.85 \mathrm{~g} / \mathrm{cm}^{3}$ determined according to UNE 80103 [33] and a Blaine specific surface of $3885 \mathrm{~cm}^{2} / \mathrm{g}$ obtained according to EN 196-6 [34]. The chemical composition of the cement is given in Table 2.

Table 2. Cement chemical composition.

\begin{tabular}{ccccccccc}
\hline \multicolumn{10}{c}{ Composition (wt.\%) } \\
\hline $\mathrm{CaO}$ & $\mathrm{SiO}_{2}$ & $\mathrm{Al}_{\mathbf{2}} \mathrm{O}_{\mathbf{3}}$ & $\mathrm{Fe}_{\mathbf{2}} \mathrm{O}_{3}$ & $\mathbf{M g O}$ & $\mathbf{K}_{\mathbf{2}} \mathrm{O}$ & $\mathbf{S O}_{3}$ & Ignition Loss \\
\hline CEM IV & 35.5 & 41.2 & 13.3 & 4.4 & 1.2 & 1.4 & 1.3 & 1.7 \\
\hline
\end{tabular}

\subsection{Mix Proportions}

Three self-compacting recycled concretes were mixed with recycled aggregates from out-of-use track elements: the first, exclusively with RA-B, called RC-B; the second, exclusively with RA-S, called RC-S; and finally, a third concrete with both types of aggregates in the proportion in which these wastes were found in a ballast track, called RC-M. Table 3 shows the three mix proportions.

Table 3. Mix proportions.

\begin{tabular}{cccc}
\hline Material & RC-B & RC-S & RC-M \\
\hline Water & 225 & 200 & 221 \\
Cement & 500 & 500 & 500 \\
Superplasticizer additive & 10 & 10 & 10 \\
RA-FBS & 790 & - & 677 \\
RA-BS & 320 & - & 274 \\
RA-BCA & 522 & - & 447 \\
RA-FSS & - & 690 & 98 \\
RA-SS & - & 283 & 40 \\
RA-SCA & - & 587 & 83 \\
Water/cement ratio & 0.45 & 0.40 & 0.44 \\
$\%$ sand (0-2 mm) from the total sand & 70 & 70 & 70 \\
$\%$ coarse aggregate from the total aggregates & 35 & 40 & 36 \\
$\%$ superplasticizer additive/cement & 2.00 & 2.00 & 2.00 \\
\hline
\end{tabular}


It should be noted that the mix proportions were determined using the criteria that the three self-compacting concretes had a similar workability; therefore, as the RA-B-CA had a notably sharper geometry than the RA-S-CA, it was necessary to increase the amount of water to achieve the same workability [35].

\subsection{Mechanical Properties}

The compressive strength tests were performed according to the EN 12390-3 and EN 13290-3/AC [36,37] standards, using cubes of $100 \mathrm{~mm}$ side at ages of 1, 2, 3, 5, 7, 28, 90 and 180 days, testing 5 specimens for each age and material. The stabilized secant moduli of elasticity was determined according to EN 12390-13 [38] using cylindrical specimens of $200 \mathrm{~mm}$ in height and $100 \mathrm{~mm}$ in diameter at the ages of 7, 28,90 and 180 days, testing 2 specimens for each age and material.

\subsection{Fatigue Tests}

The influence of conducting trials at a very high frequency was analyzed. For this purpose, the reference was tests carried out at moderate frequency, i.e., usual test frequencies, namely $10 \mathrm{~Hz}$. For very high frequency tests, the highest possible test frequency was used, namely, tests were performed on a resonant fatigue machine. This machine carried out the tests at the resonance frequency of the set test machine and the specimen. In the specific case of the resonance machine used and the specimens used, these resonance frequencies were in the range of $90 \pm 5 \mathrm{~Hz}$.

An explicative scheme of the fatigue tests that were carried out can be found in Figure 2a. Fatigue tests at both a moderate frequency $(10 \mathrm{~Hz})$ and a very high frequency $(90 \mathrm{~Hz})$ were performed using cylindrical specimens of $200 \mathrm{~mm}$ in height and $100 \mathrm{~mm}$ in diameter in all tests when these specimens were older than 90 days; this was done to ensure that the properties of the concrete had reached a stationary state. All the tests carried out recorded both the load applied to the specimen and the evolution of the strain suffered by the specimen. The strain was recorded by means of two strain gauges fixed to the specimens in two diametrically opposed generatrixes by considering the mean of the values provided by both gauges as the strain value of the specimen. In the high-frequency tests, the frequency at which the system was located was recorded, noting that the resonant frequency of the system will evolve with the variations in its stiffness. For each of the fatigue test types, two specimens were tested, ensuring that similar results were obtained in both.

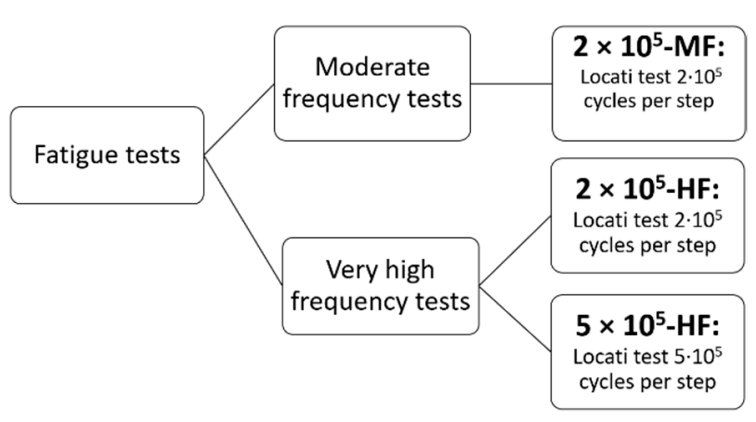

(a)

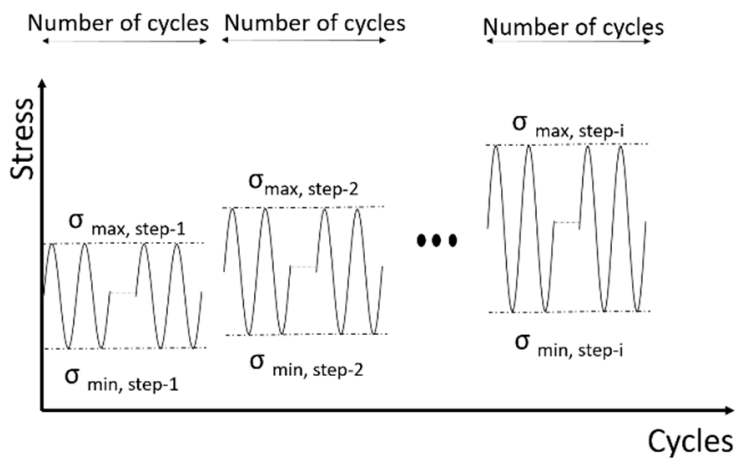

(b)

Figure 2. (a) Experimental fatigue campaign. (b) Locati methodology description. MF: moderate frequency, HF: high frequency.

Fatigue characterization at a moderate frequency was performed using the Locati method [39,40]. The Locati methodology consists of applying increasing steps of sinusoidal loads, maintaining a constant ratio $\sigma_{\max } / \sigma_{\min }=0.1$ over a constant number of cycles, in this case $2 \times 10^{5}$ cycles (Figure $2 \mathrm{~b}$ ). These tests were performed on a servo-hydraulic machine with a maximum capacity of $1000 \mathrm{kN}$ (Figure 2b). The criterion used to determine the fatigue limit using this type of test was that followed by Thomas in his $\mathrm{PhD}$ thesis [41], which obtained the fatigue limit stress range to be $80 \%$ of the stress range of the 
step in which the breaking occurs. The stress range was the difference between the maximum and minimum stress, i.e., $\Delta \sigma=\sigma_{\max }-\sigma_{\min }$. This method is called method-1.

In order to analyse whether an increase in frequency had an influence on the concrete fatigue limit, tests were performed under identical loads at a moderate frequency and a very high frequency. A 400-kN capacity machine was used to perform fatigue tests at the resonance frequency of the test set. This resonance frequency was found in all cases to be in the range $90 \pm 5 \mathrm{~Hz}$ (see Figure $3 b$ ). In this case, in addition to analysing the results following the procedure followed by Thomas in his $\mathrm{PhD}$ thesis [41], an additional failure criterion was introduced, namely, to define the stress range of the step prior to a resonance frequency drop as the stress range of the endurance limit. This method was denominated as method-2.

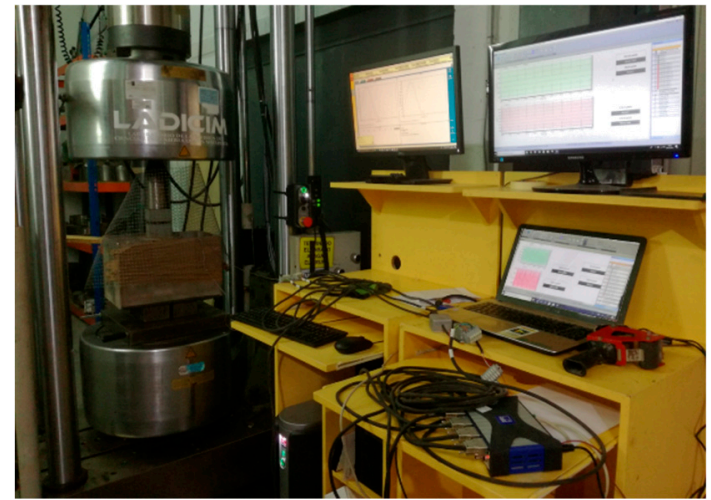

(a)

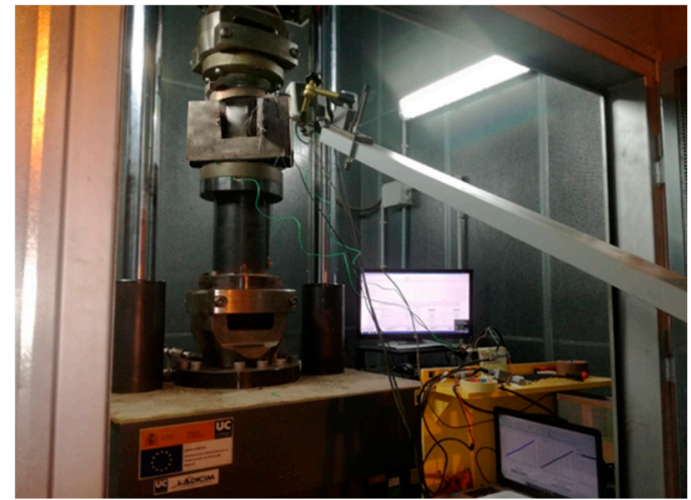

(b)

Figure 3. Fatigue tests. (a) Low-frequency fatigue testing and (b) high-frequency fatigue testing.

In order to analyse the influence of the number of cycles in the Locati tests, very high frequency tests were performed with the same stress values but applying $5 \times 10^{5}$ cycles per step instead of $2 \times 10^{5}$ cycles. For these tests, the same testing machine was used, and the same criteria were used to define the endurance tension range.

The common objective of all these studies was to determine the step associated with the fatigue limit of the concrete in each case. In order to be able to compare the results as directly as possible, it was decided to fix the load steps based on the compressive strength of each material. For this purpose, the value of the maximum stress of each step was defined as a coefficient $(k)$ multiplied by the compressive strength at the time the fatigue tests began, that is, 90 days after manufacture of each of the concretes; furthermore, the tensional ratio $\sigma_{\max } / \sigma_{\min }$ was set to 0.1 . Table 4 shows a summary of the tension values used in each of the load steps applied.

Table 4. Fatigue test stress values.

\begin{tabular}{|c|c|c|c|c|c|c|c|c|c|c|}
\hline \multirow{2}{*}{$\mathbf{N}$} & \multirow{2}{*}{$\mathbf{k}$} & \multicolumn{3}{|c|}{ RC-B } & \multicolumn{3}{|c|}{ RC-S } & \multicolumn{3}{|c|}{ RC-M } \\
\hline & & $\begin{array}{c}\sigma_{\max } \\
(\mathrm{MPa})\end{array}$ & $\begin{array}{c}\sigma_{\min } \\
(\mathrm{MPa})\end{array}$ & $\begin{array}{l}\text { Range } \\
\text { (MPa) }\end{array}$ & $\begin{array}{c}\sigma_{\max } \\
(\mathrm{MPa})\end{array}$ & $\begin{array}{c}\sigma_{\min } \\
(\mathrm{MPa})\end{array}$ & $\begin{array}{l}\text { Range } \\
\text { (MPa) }\end{array}$ & $\begin{array}{c}\sigma_{\max } \\
(\mathrm{MPa})\end{array}$ & $\begin{array}{c}\sigma_{\min } \\
(\mathrm{MPa})\end{array}$ & $\begin{array}{l}\text { Range } \\
\text { (MPa) }\end{array}$ \\
\hline 1 & 0.30 & 17.8 & 1.8 & 16.0 & 23.3 & 2.3 & 21.0 & 18.9 & 1.9 & 17.0 \\
\hline 2 & 0.35 & 20.8 & 2.1 & 18.7 & 27.2 & 2.7 & 24.5 & 22.0 & 2.2 & 19.8 \\
\hline 3 & 0.40 & 23.8 & 2.4 & 21.4 & 31.1 & 3.1 & 28.0 & 25.1 & 2.5 & 22.6 \\
\hline 4 & 0.45 & 26.7 & 2.7 & 24.0 & 35.0 & 3.5 & 31.5 & 28.3 & 2.8 & 25.5 \\
\hline 5 & 0.50 & 29.7 & 3.0 & 26.7 & 38.9 & 3.9 & 35.0 & 31.4 & 3.1 & 28.3 \\
\hline 6 & 0.55 & 32.7 & 3.3 & 29.4 & 42.8 & 4.3 & 38.5 & 34.6 & 3.5 & 31.1 \\
\hline 7 & 0.60 & 35.7 & 3.6 & 32.1 & 46.7 & 4.7 & 42.0 & 37.7 & 3.8 & 33.9 \\
\hline 8 & 0.65 & 38.6 & 3.9 & 34.7 & 50.6 & 5.1 & 45.5 & 40.8 & 4.1 & 36.7 \\
\hline 9 & 0.70 & 41.6 & 4.2 & 37.4 & 54.5 & 5.4 & 49.1 & 44.0 & 4.4 & 39.6 \\
\hline
\end{tabular}


In order to compare the degree of influence of repeated loads on each of the materials, the influence coefficient (IC) was defined as the ratio of the stress range corresponding to the fatigue limit of the concrete to its compressive strength.

\section{Results and Discussions}

\subsection{Compressive Strength and Young's Modulus}

Figure 4 shows the evolution of the compressive strength as a function of time, while Figure 5 shows the evolution of Young's modulus as a function of the age of the different concretes.

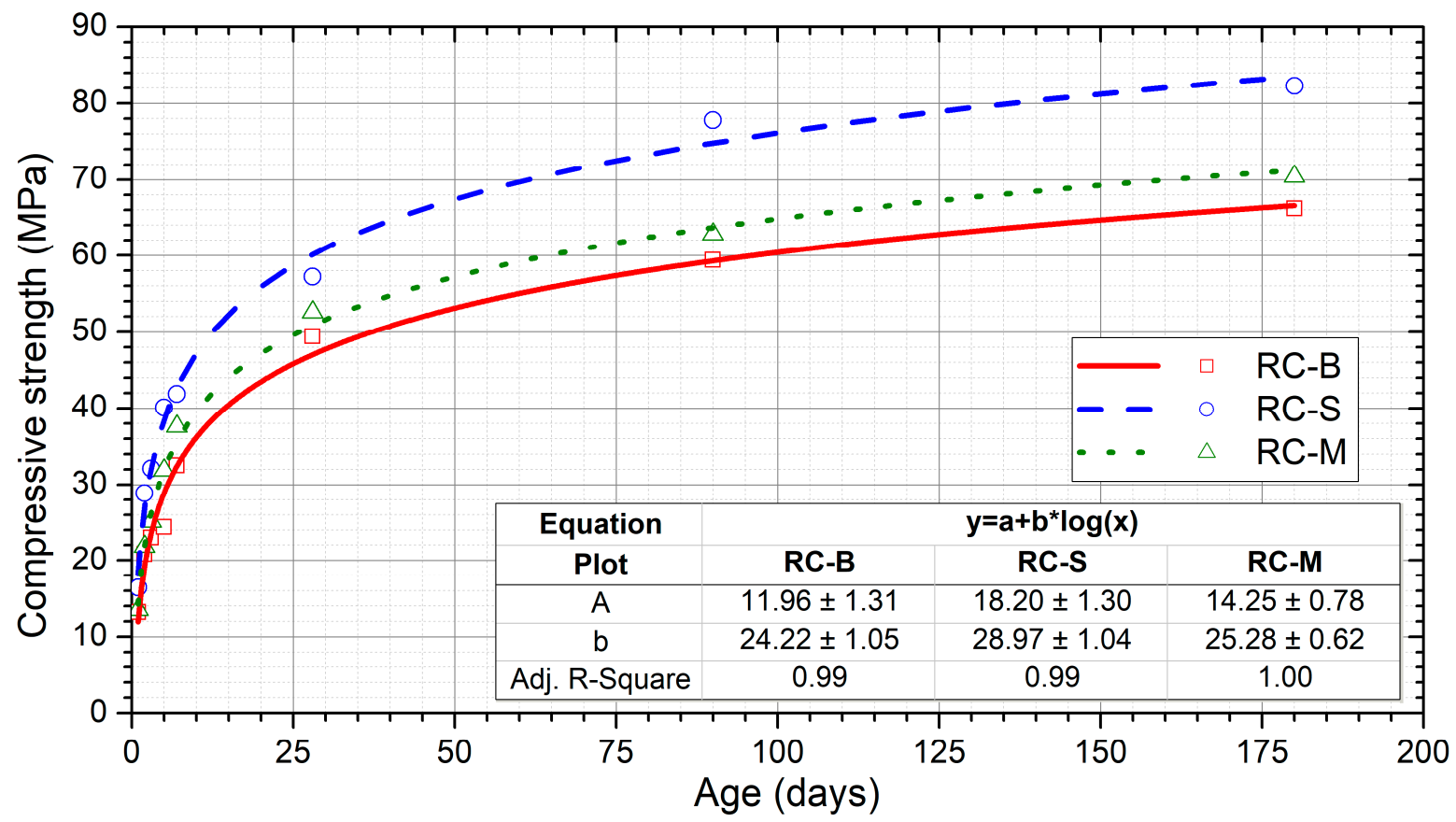

Figure 4. Evolution of the compressive strength.

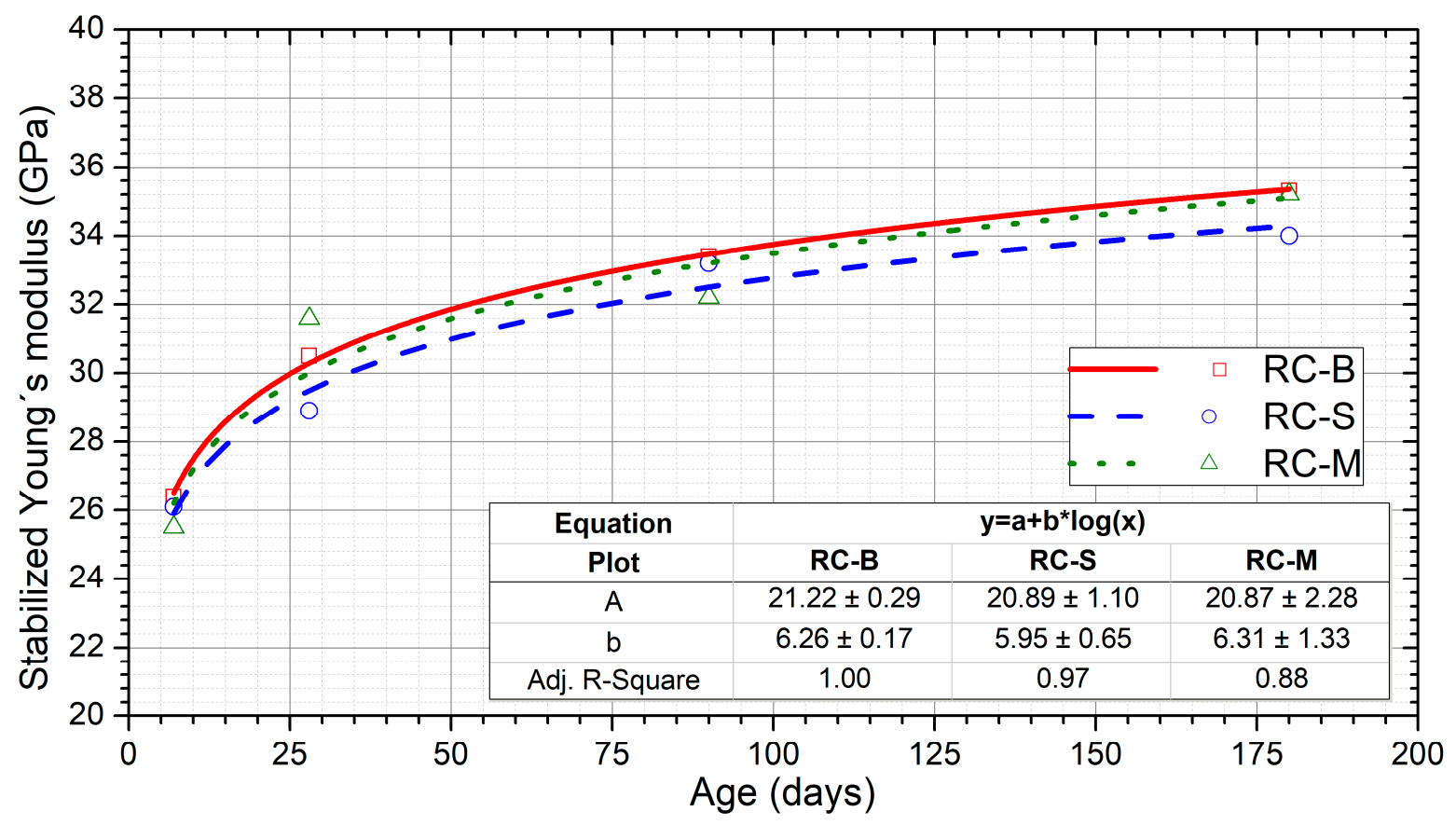

Figure 5. Evolution of the Young's modulus. 
The great influence of the water/cement ratio on the compressive strength of the RC-S can be observed. On the other hand, RC-B had the lowest compressive strengths and RC-M had intermediate compressive strengths between the other two concretes.

In the case of Young's modulus, although the RC-S paste was of a better quality than that of RC-B, the noticeably lower stiffness of the mortar, adhered to the natural aggregates that made up the RA-S, meant that the elastic modulus of RC-S was lower than that of RC-B. As in the case of the compressive strength, RC-M was found between RC-B and RC-S concretes in all cases.

\subsection{Influence of the Frequency on Fatigue}

Figure 6 shows an example of the maximum deformation envelope recorded during the Locati tests at a frequency of $10 \mathrm{~Hz}$.

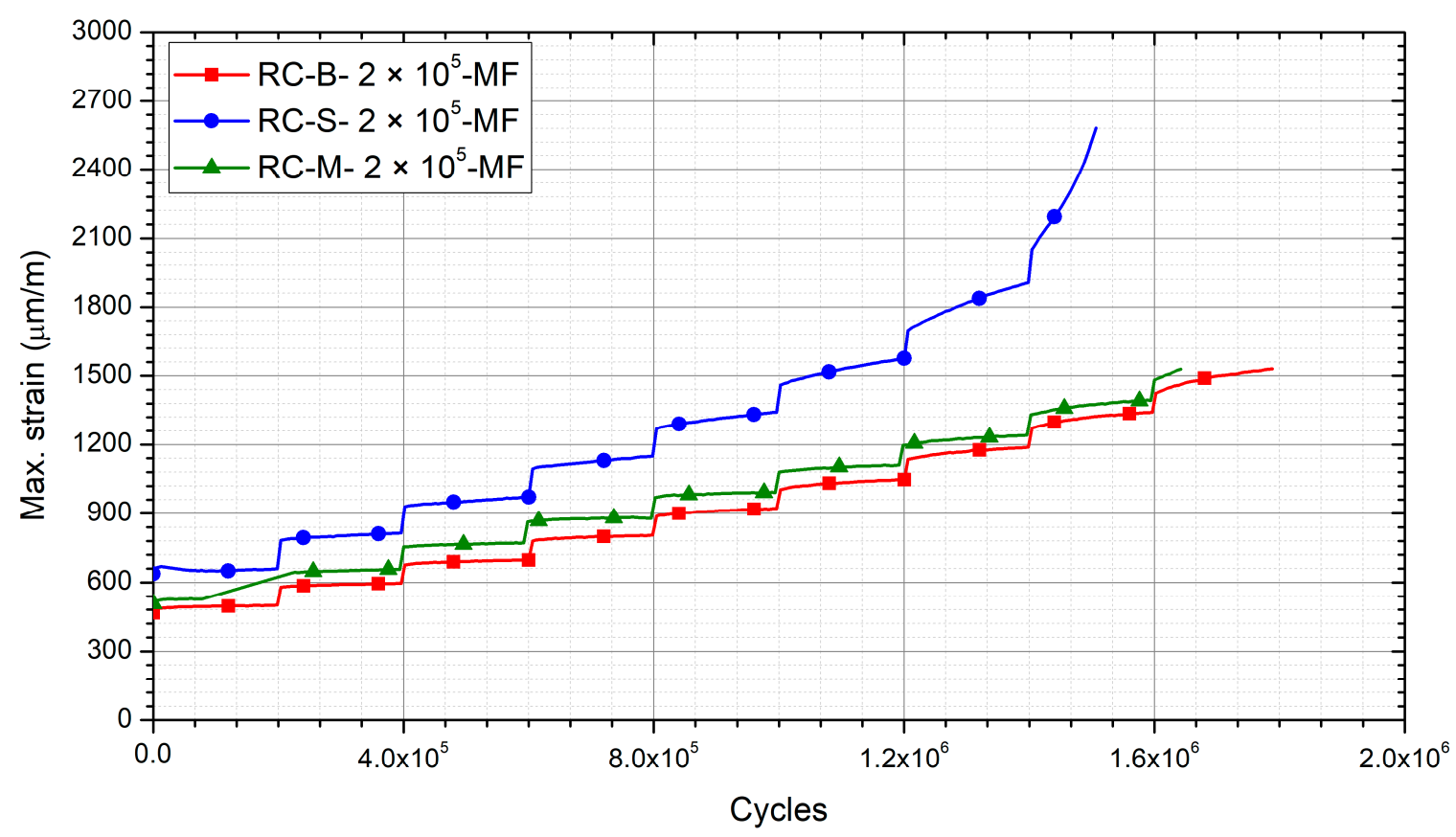

Figure 6. Maximum strain of low-frequency Locati fatigue tests with $2 \times 10^{5}$ cycles per step.

Figure 6 shows, first of all, that RC-B was able to resist the most steps, which meant that it was the material with the highest IC, with RC-S being able to resist the least and RC-M was in an intermediate situation between the other two materials. These results agree with the results of other authors who state that the presence of adhered mortar in the RA reduces this coefficient $[15,16,42]$. It can also be seen that the deformation values suffered by the specimens was lower in the case of RC-B. It should be noted that, as each of the steps is a fixed percentage compared to the compressive strength of each material, they are not directly comparable to each other as they are different stress values.

Table 5 shows a brief summary of the results obtained from the moderate-frequency tests carried out using method-1.

Table 5. Low-frequency fatigue limit $\left(\mathrm{f}_{\mathrm{L}}\right)$ obtained using the Locati method with $2 \times 10^{5}$ cycles per step. IC: influence coefficient.

\begin{tabular}{cccc}
\hline \multirow{2}{*}{ Material } & $\Delta \boldsymbol{\sigma}_{\max }$ & $\mathbf{f}_{\mathbf{L}}$ & $\mathbf{I C}$ \\
\cline { 2 - 4 } & $\mathbf{( M P a )}$ & $\mathbf{( M P a )}$ & $\mathbf{( \% )}$ \\
\hline RC-B & 38.75 & 31.0 & 52.2 \\
RC-S & 45.5 & 36.4 & 46.8 \\
RC-M & 39.6 & 31.7 & 50.4 \\
\hline
\end{tabular}


Analysis of these results shows that the material with the highest stress range was RC-S, the least was RC-B and the RC-M had an intermediate value. Likewise, it is possible to determine that, although the RC-S had the highest stress range values, it had the lowest IC. This loss of compressive strength was due to the presence of mortar adhered to the aggregate. In any case, these values of IC are within the usual range for concretes and agree with values found in the literature $[15,16]$.

Figure 7 shows an example of the maximum deformation suffered by a specimen of each material during Locati tests at the resonance frequency of the machine test set.

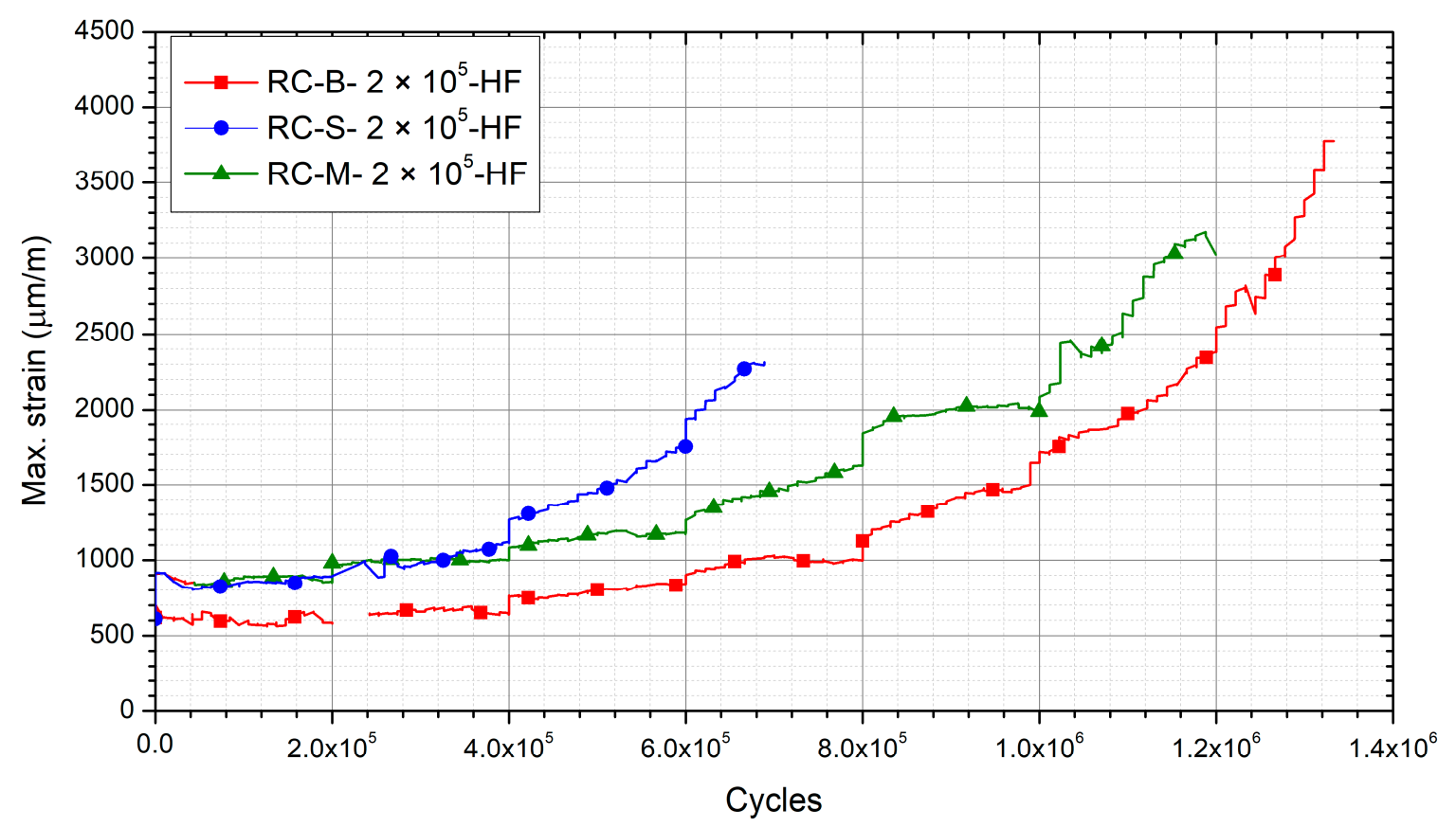

Figure 7. Maximum strain of high-frequency Locati fatigue tests with $2 \times 10^{5}$ cycles per step.

Figure 7 shows that RC-S was the material that had the lowest IC. RC-M was generally between RC-B and RC-S.

Figure 8 shows that the resonance frequency evolved throughout the test. For the first steps, there was an increase in the frequency with the cycles throughout each step, as well as a punctual increase when there was a change of step. At the end of each test, a drop in the resonance frequency of the system was seen. This resonance frequency depended on the stiffness of the system; an increase in the stiffness of the system resulted in an increase in the resonance frequency, while a reduction in the stiffness of the system reduced it. For this reason, it was interpreted that both point and distributed frequency increases occurred as a consequence of a stiffening of the system, while the fall that occurred in the final part of the test was a consequence of the damage suffered by the specimen, where the cracks had reached such a size that they produced a flexibilization of the specimen, which indicated that it was close to breaking. 


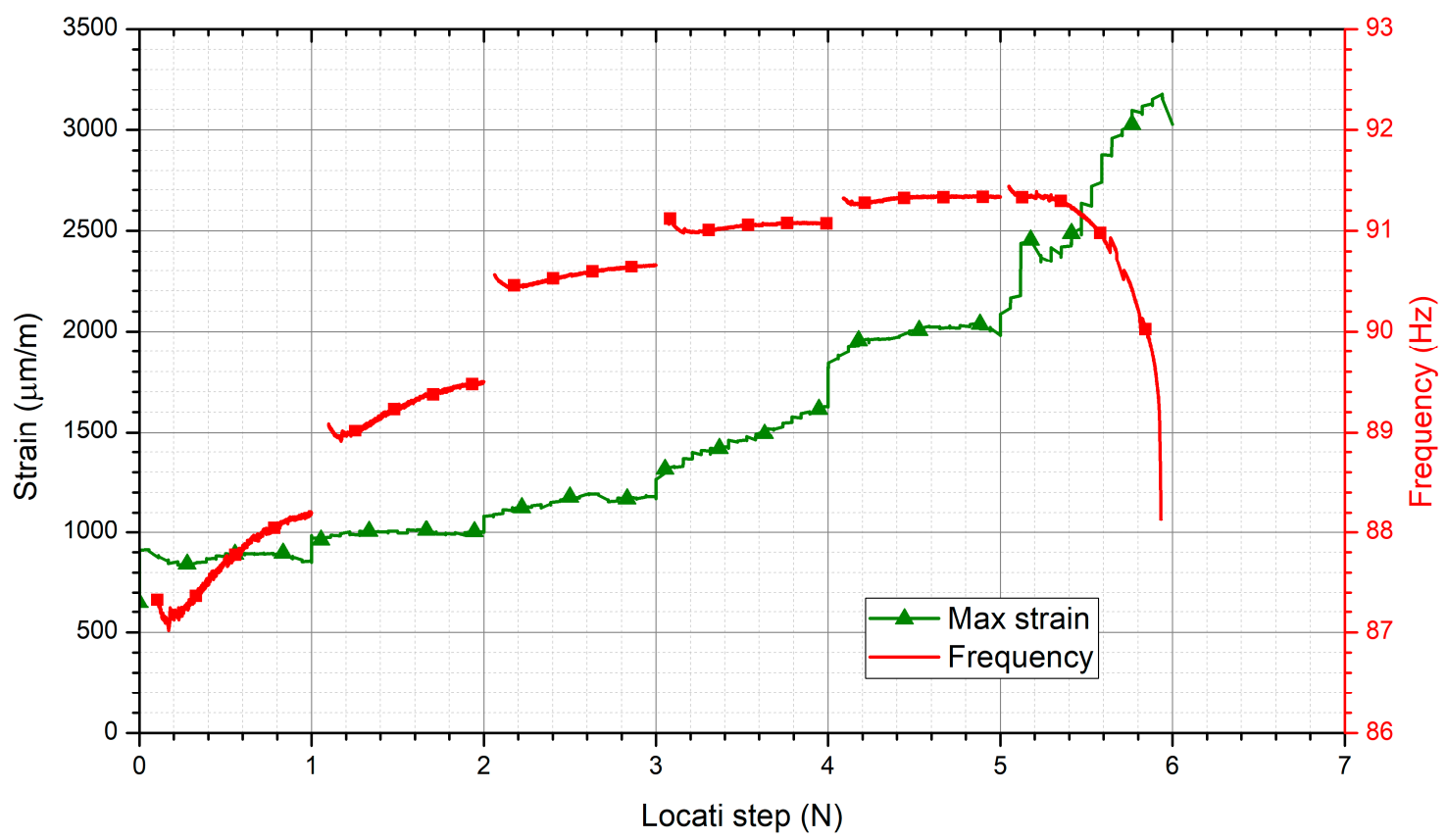

Figure 8. Maximum strain and resonance frequency comparison during high-frequency Locati fatigue tests with $2 \times 10^{5}$ cycles per step.

Table 6 shows the results obtained from the Locati tests with $2 \times 10^{5}$ cycles per step at a very high frequency using the two criteria previously established.

Table 6. High-frequency fatigue limit obtained using the Locati method with $2 \times 10^{5}$ cycles per step.

\begin{tabular}{cccccc}
\hline \multirow{2}{*}{ Material } & \multicolumn{2}{c}{ Method-1 } & \multicolumn{2}{c}{ Method-2 } \\
\cline { 2 - 6 } & $\boldsymbol{\Delta} \boldsymbol{\sigma}_{\max }$ & $\mathbf{f}_{\mathbf{L}}$ & $\mathbf{I C}$ & $\mathbf{f}_{\mathbf{L}}$ & $\mathbf{I C}$ \\
\cline { 2 - 6 } & $\mathbf{( M P a )}$ & $\mathbf{( M P a}]$ & $\mathbf{( \% )}$ & $\mathbf{( M P a )}$ & $\mathbf{( \% )}$ \\
\hline RC-B & 32.09 & 25.67 & 43.19 & 26.74 & 44.93 \\
RC-S & 31.51 & 25.21 & 32.40 & 28.01 & 35.99 \\
RC-M & 31.10 & 24.88 & 39.60 & 28.27 & 45.04 \\
\hline
\end{tabular}

Analysing the results of Table 6, it can be determined that, as had been deduced from the evolution of the maximum strain, RC-B was the material with the highest IC, although the compression strength of RC-S was the highest of all. The stress ranges corresponding to the fatigue limit of the three concretes were similar. It can also be appreciated that, although the values of both the fatigue limit and IC, obtained using the two analysis criteria were similar, a 5\% difference was found relative to the limit provided by Thomas [41], which was usually more conservative than the one obtained using the resonance frequency.

\subsection{Influence of the Number of Cycles Per Step during a Locati Test}

In order to determine the influence of increasing the number of cycles in each step of the Locati test, identical tests were carried out to those described above, but the number of cycles per step was set at $5 \times 10^{5}$ instead of $2 \times 10^{5}$. Figure 9 shows the evolution of the maximum deformation as a function of the number of cycles throughout the Locati test for $5 \times 10^{5}$ cycles per step. 


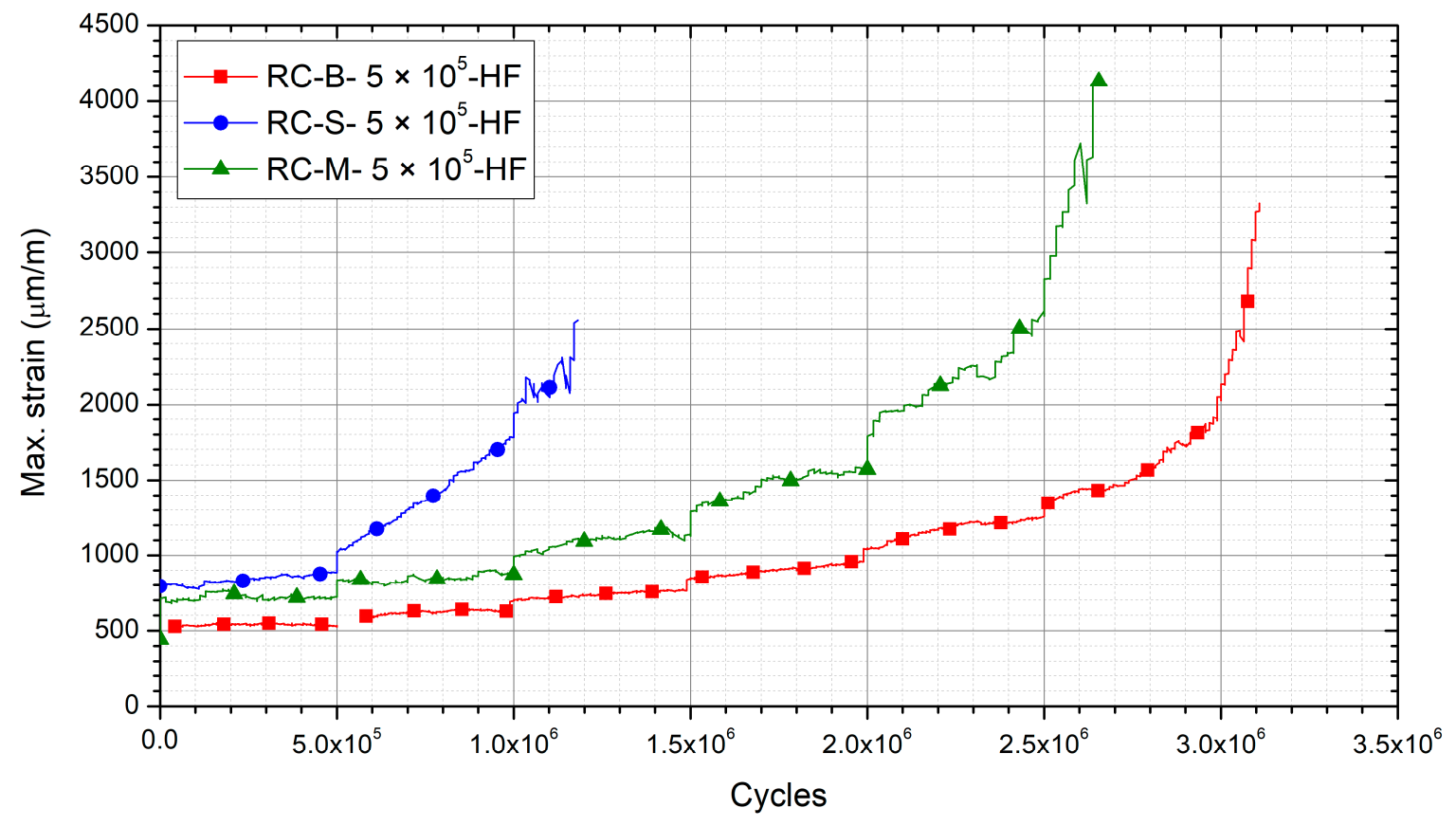

Figure 9. Maximum strain of high-frequency Locati fatigue tests with $5 \times 10^{5}$ cycles per step.

Figure 9 shows that RC-S was the material that had the lowest IC. RC-M was between RC-B and RC-S. In this case, as in the previous case, the two analysis criteria were used to determine the stress range corresponding to the fatigue limit. These results are shown in Table 7.

Table 7. High-frequency fatigue limit obtained using the Locati method with $5 \times 10^{5}$ cycles per step.

\begin{tabular}{cccccc}
\hline \multirow{2}{*}{ Material } & \multicolumn{2}{c}{ Method-1 } & \multicolumn{2}{c}{ Method-2 } \\
\cline { 2 - 6 } & $\boldsymbol{\Delta} \boldsymbol{\sigma}_{\max }$ & $\mathbf{f}_{\mathbf{L}}$ & $\mathbf{f}_{\mathbf{L}} / \mathbf{f}_{\mathbf{c}}$ & $\mathbf{f}_{\mathbf{L}}$ & $\mathbf{f}_{\mathbf{L}} / \mathbf{f}_{\mathbf{c}}$ \\
\cline { 2 - 6 } & $\mathbf{( M P a )}$ & $\mathbf{( M P a )}$ & $\mathbf{( \% )}$ & $\mathbf{( M P a )}$ & $\mathbf{( \% )}$ \\
\hline RC-B & 32.09 & 24.6 & 41.39 & 26.74 & 44.93 \\
RC-S & 29.76 & 23.81 & 30.60 & 24.51 & 31.49 \\
RC-M & 29.685 & 23.75 & 37.80 & 25.45 & 40.59 \\
\hline
\end{tabular}

In order to compare the evolution of the maximum strain throughout the test, it was decided to divide the number of cycles performed by the number of cycles per step, in this way it was be possible to compare the results of the three variants of the test. An example of the comparison between the Locati test types for each material is given in Figure 10; Figure 12.

Figure 10 shows the influence of increasing the frequency on the fatigue behaviour of the RC-B by comparing the RC-B-HF- $2 \times 10^{5}$ with the RC-B-MF- $2 \times 10^{5}$. It is possible to conclude that, in the first phase, increasing the test frequency had no influence on the deformation suffered by the specimens. After step 4, the two curves separated, increasing more rapidly in the case of RC-B-HF- $2 \times 10^{5}$. This behaviour can be justified by arguing that, in the first phase, a phase in which the concrete was not damaged, the effect of the frequency seemed irrelevant, whereas when the cracks reached a critical size, an increase in frequency produced a reduction in the number of cycles that RC-B could withstand. It was observed that the specimens tested at very high frequencies showed a markedly higher temperature increase than in the case of tests performed at moderate frequency. This fact is believed to be related to the reduction in fatigue life of the material. 


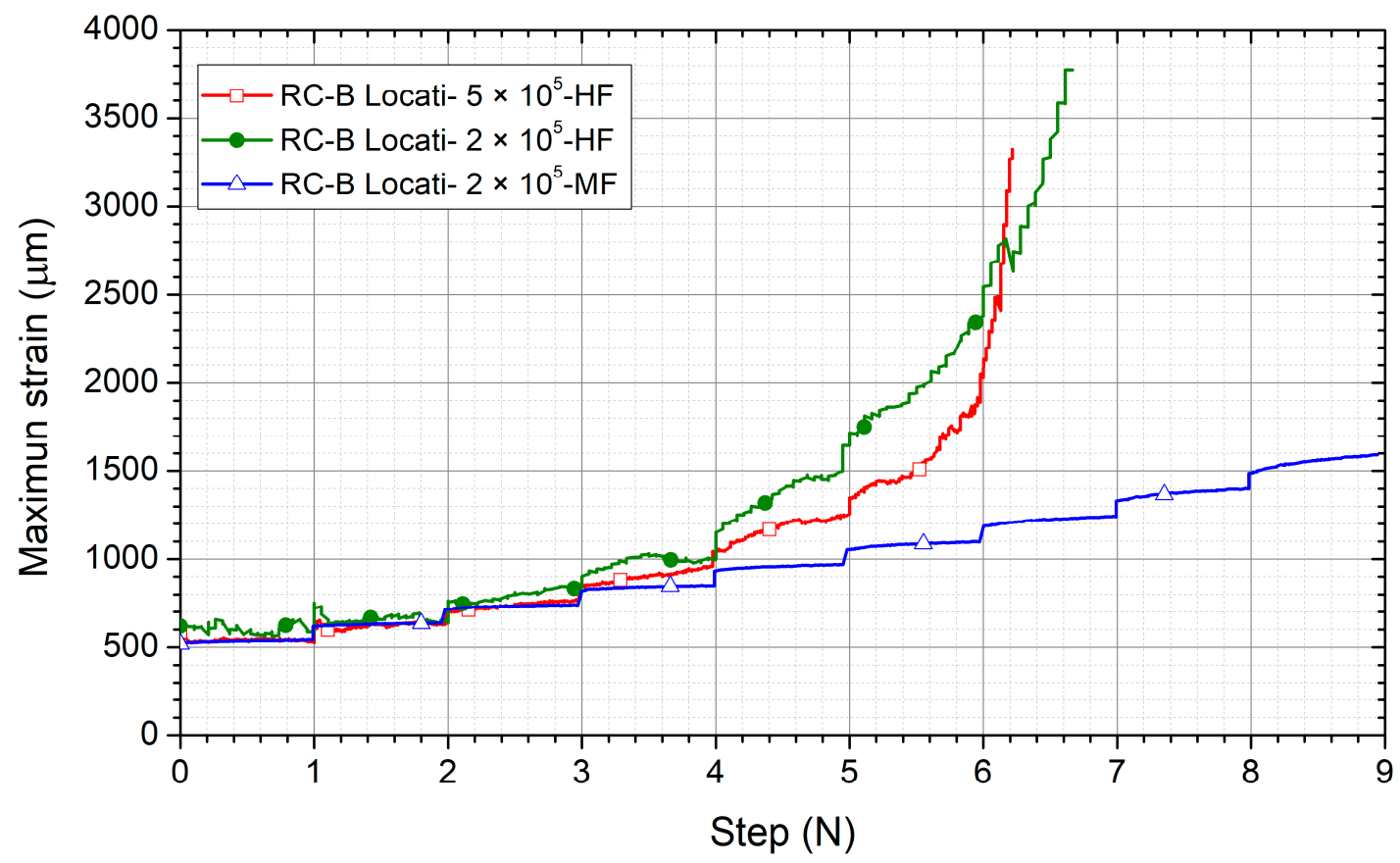

Figure 10. Comparison of the maximum strain of the RC-B for a Locati test with $2 \times 10^{5}$ cycles per step at a low frequency (RC-B-MF-2 $\times 10^{5}$ ), a Locati test with $2 \times 10^{5}$ cycles per step at a high frequency $\left(\right.$ RC-B-HF-2 $\left.\times 10^{5}\right)$ and a Locati test with $5 \times 10^{5}$ cycles per step at a high frequency $\left(\right.$ RC-B-HF- $\left.5 \times 10^{5}\right)$.

From this same Figure 10, it is also possible to analyse the influence of increasing the number of cycles per step from $2 \times 10^{5}$ to $5 \times 10^{5}$. Comparing the two curves, it is observed that the effect of each step was similar until the specimen was close to breaking. For this reason, it can be assumed that the influence of increasing the number of cycles per step during a Locati test was small given that the difference between steps had a greater influence than increasing the number of cycles per step by $150 \%$.

Figure 11 shows the influence of increasing the frequency on the fatigue behaviour of the RC-S by comparing RC-S-HF- $2 \times 10^{5}$ with RC-S-MF- $2 \times 10^{5}$. As in RC-B, it can be concluded that, in the first phase, increasing the test frequency had no impact on the deformation suffered by the specimens. From step 2, it can be seen how the two curves split, increasing more rapidly in the case of the RC-S-HF- $2 \times 10^{5}$. This effect was more severe in RC-S than in RC-B, which was reflected by a greater variation in the IC of RC-S as the test frequency increased.

Figure 11 shows the influence of increasing the number of cycles per step from $2 \times 10^{5}$ to $5 \times 10^{5}$ for RC-S. A similar behaviour to that of RC-B was observed, but in this case, the effect of increasing the number of cycles per step was greater than in RC-B, which was reflected in the accelerated separation of the curves. As in the case of RC-B, in this case, the greatest difference in fatigue limit was found between RC-B-HF- $2 \times 10^{5}$ and RC-B-HF- $5 \times 10^{5}$ and was one step; for this reason, it can be assumed that the influence of increasing the number of cycles per step during a Locati test was small, given that the jump between steps had a greater influence than increasing the number of cycles per step by $150 \%$. 


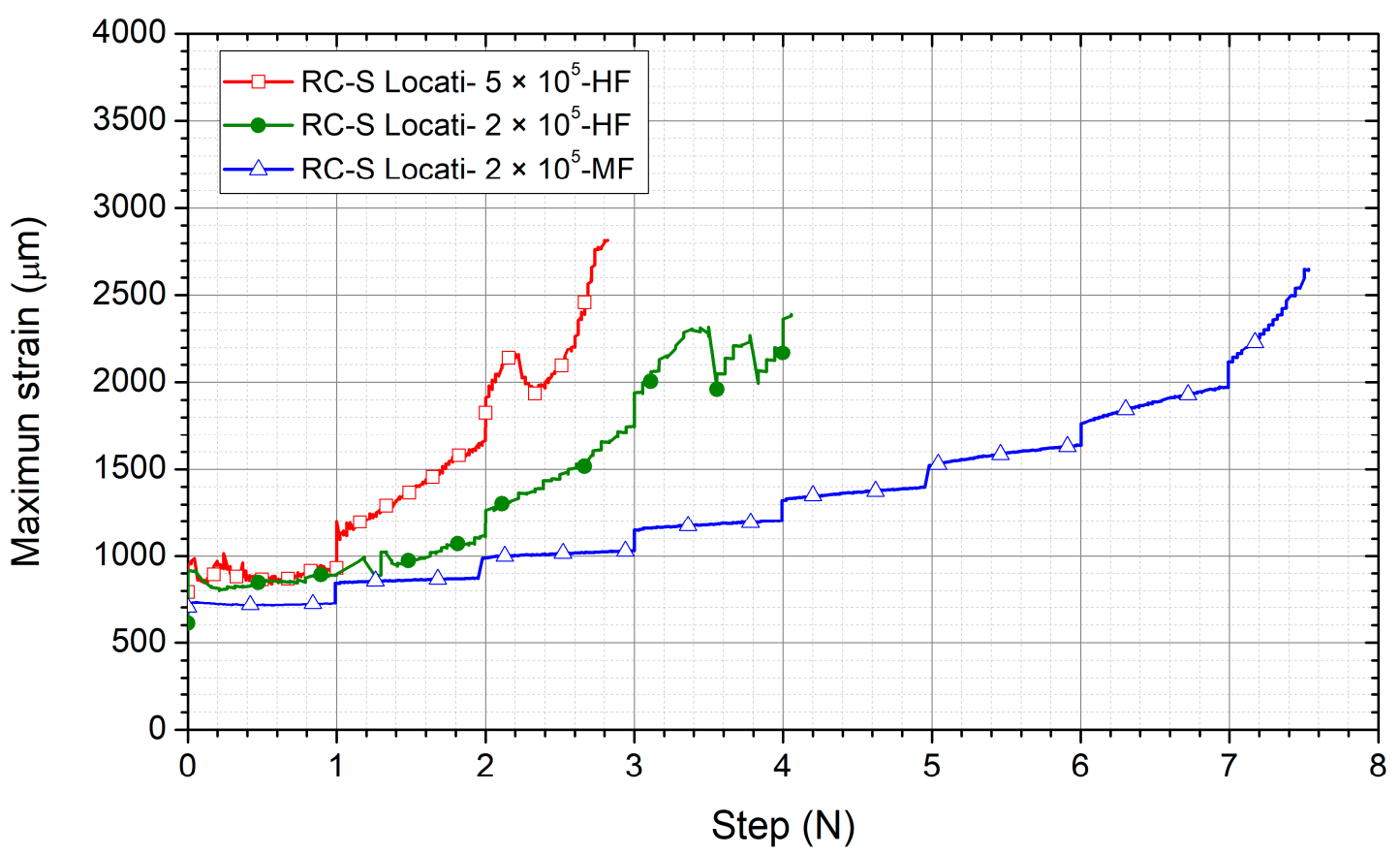

Figure 11. Comparison of the maximum strain of the RC-S for a Locati test with $2 \times 10^{5}$ cycles per step at a low frequency (RC-S-MF- $2 \times 10^{5}$ ), a Locati test with $2 \times 10^{5}$ cycles per step at a high frequency $\left(\right.$ RC-S-HF- $2 \times 10^{5}$ ) and a Locati test with $5 \times 10^{5}$ cycles per step at high frequency (RC-S-HF-5 $\times 10^{5}$ ).

In Figure 12, both the frequency and number of cycles affected the fatigue life during the Locati RC-M test. The behaviour of this material was an intermediate situation between RC-B and RC-S, being in all cases, more similar to the behaviour of RC-B.

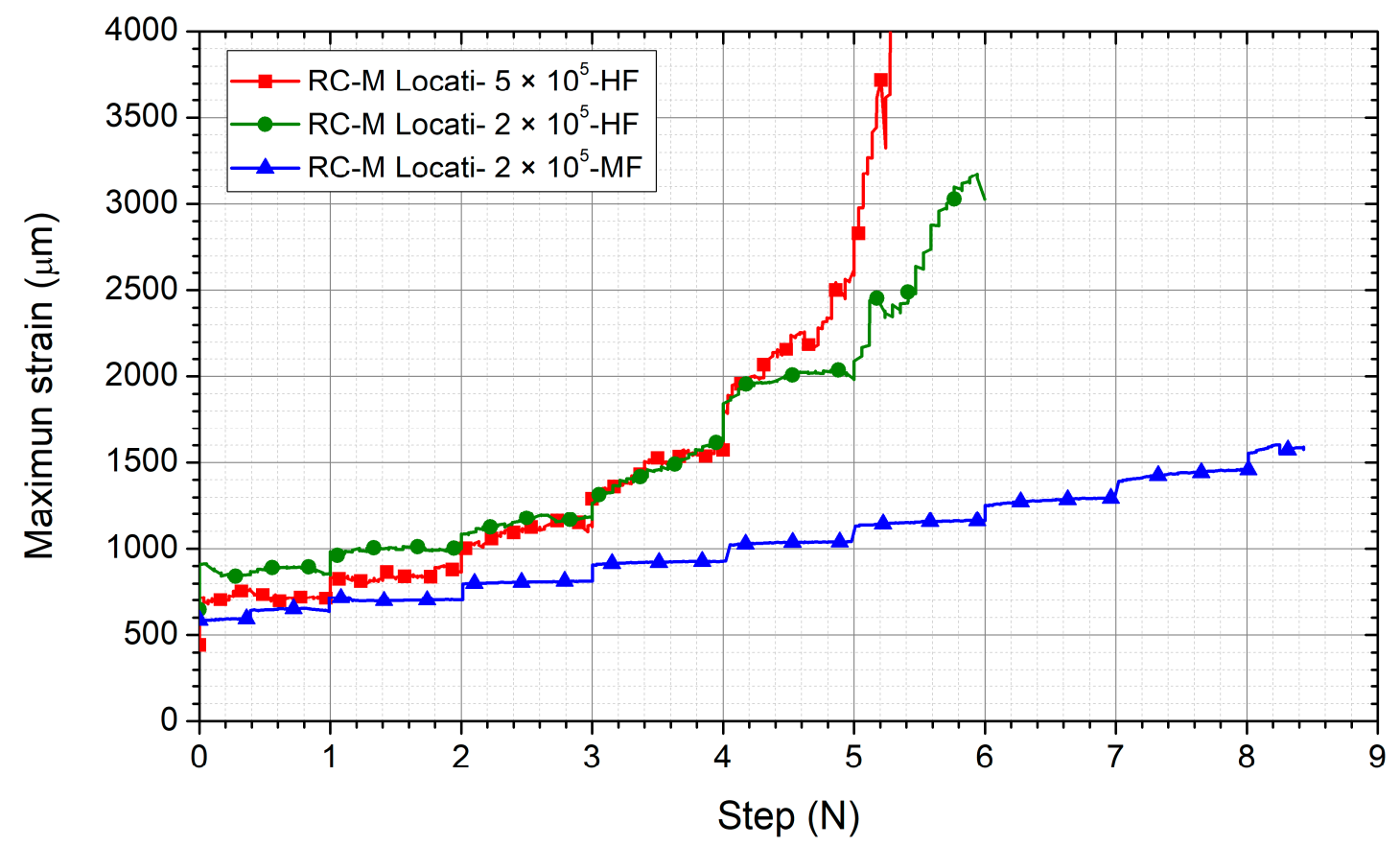

Figure 12. Comparison of the maximum strain of the RC-M for a Locati test with $2 \times 10^{5}$ cycles per step at a low frequency (RC-M-MF- $2 \times 10^{5}$ ), a Locati test with $2 \times 10^{5}$ cycles per step at a high frequency $\left(\right.$ RC-M-HF- $\left.2 \times 10^{5}\right)$ and a Locati test with $5 \times 10^{5}$ cycles per step at a high frequency $\left(\right.$ RC-M-HF- $\left.5 \times 10^{5}\right)$. 
To summarise, it can be stated that performing tests at a very high frequency reduced the number of cycles that a specimen was capable of resisting compared to performing the test at a moderate frequency. On the other hand, it was also demonstrated that $2 \times 10^{5}$ cycles per step was enough to characterize a fatigued concrete.

\subsection{Comparison of the Different Methodologies}

In this section the endurance values for each of the three concretes tested was compared using the five proposed analysis criteria. Figure 13 shows the values of the stress range corresponding to the fatigue limit of the three concretes analysed using the five previously defined procedures.
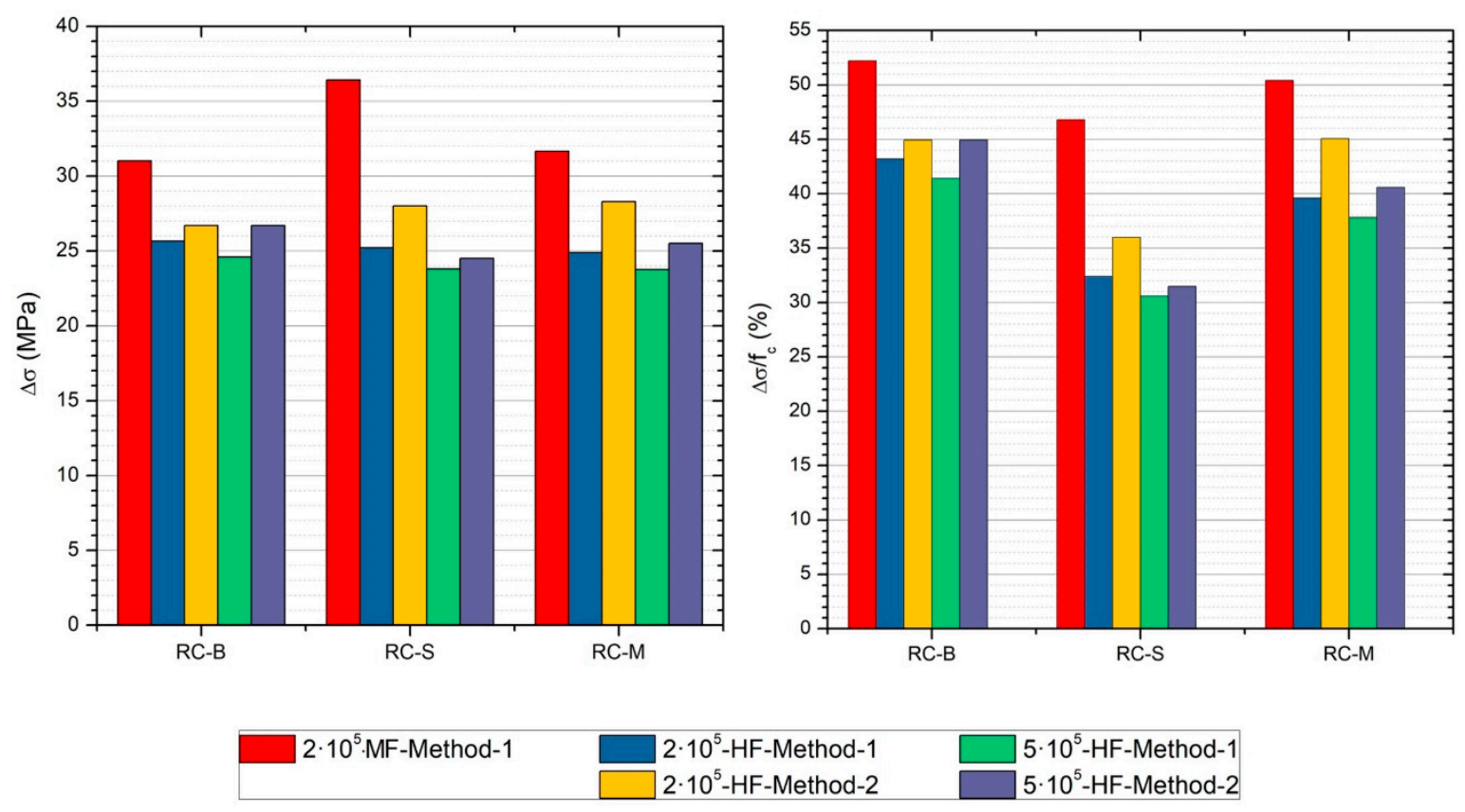

Figure 13. Comparison of the high-frequency fatigue limit obtained using five different procedures and the low-frequency fatigue limit.

It can be observed that, in all cases, the fatigue limits obtained using moderate frequency tests gave higher values than in very high frequency tests, regardless of the characterization method.

On the other hand, the two methods used to determine the fatigue limit at a very high frequency produced similar values in all cases, where the one that defines the fatigue limit as $80 \%$ of the tension range of the breaking step being more conservative in all cases. This was due to the weakness introduced by the mortar adhered to the aggregates, as well as RC-S being the material most affected by creep.

\section{Conclusions}

Although concrete is a material that is not usually characterized under fatigue, there is no doubt that there are certain elements typically made from concrete that are subjected to variable loads, and therefore, which need to be characterized under fatigue. In this work, three types of concrete were characterised under fatigue using the Locati accelerated fatigue method. Fatigue tests were carried out to analyse two fundamental variables in the duration of the tests, namely the frequency of testing and the number of cycles per step of the Locati method. The following conclusions can be observed from the results obtained:

- In all cases, the material with the lowest fatigue limit/compression resistance ratio was RC-S, which was due to the weakness introduced by the mortar adhered to the aggregates. 
- The Locati method was validated as a method to determine the fatigue limit, showing that $2 \times 10^{5}$ cycles per step was enough to determine the fatigue limit.

- It was found that the resonance frequency of the system was a parameter that could enable the identification of sensitive variations in the stiffness of the whole, and a symptom that the specimen was close to breaking. For this reason, the stress range of the step prior to the step in which a drop in the resonance frequency of the system occurs was defined as the criterion for determining the fatigue limit by means of the Locati tests.

- It is proposed that during very high frequency tests there is an increase in temperature that may reduce the fatigue life of the concrete. This study opens the door to the analysis of this hypothesis, which may explain why an increase in frequency reduces the fatigue life of the elements.

Author Contributions: J.S.-A.: investigation, methodology, formal analysis, writing original draft. C.T.: formal analysis, surpervision, writing original draft, review and editing. I.C.: founding, methodology, formal analysis, surpervision, review and editing. J.A.P.: methodology, formal analysis, surpervision, review and editing. All authors have read and agreed to the published version of the manuscript.

Funding: This research was funded Ministerio de Economía y Competitividad grant number MAT2014-57544-R.

Acknowledgments: The authors would like to thank The LADICIM, Laboratory of Materials Science and Engineering of the University of Cantabria and Instituto Superior Técnico of the University of Lisbon for making the facilities used in this research available to the authors.

Conflicts of Interest: The authors declare no conflict of interest.

\section{References}

1. Alnahhal, M.F.; Alengaram, U.J.; Jumaat, M.Z.; Abutaha, F.; Alqedra, M.A.; Nayaka, R.R. Assessment on engineering properties and $\mathrm{CO}_{2}$ emissions of recycled aggregate concrete incorporating waste products as supplements to Portland cement. J. Clean. Prod. 2018, 203, 822-835. [CrossRef]

2. Meyer, C. The greening of the concrete industry. Cem. Concr. Compos. 2009, 31, 601-605. [CrossRef]

3. Poon, C.-S.; Chan, D. The use of recycled aggregate in concrete in Hong Kong, Resour. Conserv. Recycl. 2007, 50, 293-305. [CrossRef]

4. De Brito, J.; Ferreira, J.; Pacheco, J.; Soares, D.; Guerreiro, M. Structural, material, mechanical and durability properties and behaviour of recycled aggregates concrete. J. Build. Eng. 2016, 6, 1-16. [CrossRef]

5. Thomas, C.; Setién, J.; Polanco, J.A.J.; Alaejos, P.; de Juan, M.S.; de Juan, M.S. Durability of recycled aggregate concrete. Constr. Build. Mater. 2013, 40, 1054-1065. [CrossRef]

6. De Schutter, G.; Audenaert, K. Report 38: Durability of Self-Compacting Concrete-State-of-the-Art Report of RILEM Technical Committee 205-DSC; RILEM Publications: Paris, France, 2007.

7. Kou, S.C.C.; Poon, C.S.S. Properties of self-compacting concrete prepared with coarse and fine recycled concrete aggregates. Cem. Concr. Compos. 2009, 31, 622-627. [CrossRef]

8. Kareem, A.I.; Nikraz, H.; Asadi, H. Performance of hot-mix asphalt produced with double coated recycled concrete aggregates. Constr. Build. Mater. 2019, 205, 425-433. [CrossRef]

9. Sainz-Aja, J.A.; Pombo, J.; Tholken, D.; Carrascal, I.; Polanco, J.; Ferreno, D.; Casado, J.; Diego, S.; Pérez, A.; Filho, J.A.; et al. Dynamic Calibration of Slab Track Models for Railway Applications using Full-Scale Testing. Comput. Struct. 2020, 228, 106180. [CrossRef]

10. Alliche, A. Damage model for fatigue loading of concrete. Int. J. Fatigue 2004, 26, 915-921. [CrossRef]

11. Xiao, J.; Li, H.; Yang, Z. Fatigue behavior of recycled aggregate concrete under compression and bending cyclic loadings. Constr. Build. Mater. 2013, 38, 681-688. [CrossRef]

12. Skarżyński, Ł.; Marzec, I.; Tejchman, J. Fracture evolution in concrete compressive fatigue experiments based on X-ray micro-CT images. Int. J. Fatigue 2019, 122, 256-272. [CrossRef]

13. Khosravani, M.R.; Wagner, P.; Fröhlich, D.; Weinberg, K. Dynamic fracture investigations of ultra-high performance concrete by spalling tests. Eng. Struct. 2019, 201, 109844. [CrossRef]

14. Li, Q.; Huang, B.; Xu, S.; Zhou, B.; Yu, R.C. Compressive fatigue damage and failure mechanism of fiber reinforced cementitious material with high ductility. Cem. Concr. Res. 2016, 90, 174-183. [CrossRef]

15. Thomas, C.; Setién, J.; Polanco, J.A.A.; Lombillo, I.; Cimentada, A. Fatigue limit of recycled aggregate concrete. Constr. Build. Mater. 2014, 52, 146-154. [CrossRef] 
16. Thomas, C.; Sosa, I.; Setién, J.; Polanco, J.A.; Cimentada, A.I. Evaluation of the fatigue behavior of recycled aggregate concrete. J. Clean. Prod. 2014, 65, 397-405. [CrossRef]

17. Vicente, M.A.; Mínguez, J.; González, D.C. Computed tomography scanning of the internal microstructure, crack mechanisms, and structural behavior of fiber-reinforced concrete under static and cyclic bending tests. Int. J. Fatigue 2019, 121, 9-19. [CrossRef]

18. Thomas, C.; de Brito, J.; Gil, V.; Sainz-Aja, J.A.; Cimentada, A. Multiple recycled aggregate properties analysed by X-ray microtomography. Constr. Build. Mater. 2018, 166, 171-180. [CrossRef]

19. Thomas, C.; de Brito, J.; Cimentada, A.; Sainz-Aja, J.A. Macro-and micro-properties of multi-recycled aggregate concrete. J. Clean. Prod. 2019, 118843. [CrossRef]

20. Sainz-Aja, J.A.; Carrascal, I.A.; Polanco, J.; Sosa, I.; Thomas, C. Análisis del comportamiento a fatiga de morteros con áridos reciclados provenientes de vía de ferrocarril. In Proceedings of the REHABEND 2018, Caceres, Spain, 15-18 May 2018; pp. 1313-1322.

21. Sainz-Aja, J.; Carrascal, I.; Polanco, J.A.; Thomas, C. Fatigue failure micromechanisms in ed aggregate mortar by $\mu \mathrm{CT}$ analysis. J. Build. Eng. 2019, 101027. [CrossRef]

22. Carloni, C.; Subramaniam, K.V. Investigation of sub-critical fatigue crack growth in FRP/concrete cohesive interface using digital image analysis. Compos. Part B Eng. 2013, 51, 35-43. [CrossRef]

23. Rep, C.; Hanson, J.M.; Ballinger, C.A.; Linger, D. Considerations for Design of Concrete Structures Subjected to Fatigue Loading. J Am. Concr. Inst. 1974, 71, 97-121.

24. European Concrete Committee, Ceb Committee GTG 15. Fatigue of Concrete Structures; CEB Bulletin d'information, No 188; CEB-FIP: Lausanne, Switzerland, 1988.

25. Lantsoght, E.O.L.; van der Veen, C.; de Boer, A. Proposal for the fatigue strength of concrete under cycles of compression. Constr. Build. Mater. 2016, 107, 138-156. [CrossRef]

26. Balázs, G.L. Fatigue of bond. ACI Mater. J. 1991, 88, 620-629.

27. Vicente, M.A.; Ruiz, G.; González, D.C.; Mínguez, J.; Tarifa, M.; Zhang, X. CT-Scan study of crack patterns of fiber-reinforced concrete loaded monotonically and under low-cycle fatigue. Int. J. Fatigue 2018, 114, $138-147$. [CrossRef]

28. Yoris, A.; Thomas, C.; Medina, C.; Polanco, J.A.; de Rojas, M.I.S.; Frias, M.; Cantero, B. Comportamiento a fatiga resonante en compresión de hormigones reciclados para uso estructural. In Proceedings of the 7th Euro-American Congress on Construction Pathology, Rehabilitation Technology and Heritage Management, REHABEND 2018, Caceres, Spain, 15-18 May 2018; pp. 1460-1467.

29. Medeiros, A.; Zhang, X.; Ruiz, G.; Yu, R.C.; Velasco, M.d.L. Effect of the loading frequency on the compressive fatigue behavior of plain and fiber reinforced concrete. Int. J. Fatigue 2015, 70, 342-350. [CrossRef]

30. Murdock, J.W. A Critical Review of Research on Fatigue of Plain Concrete; University of Illinois at Urbana Champaign, College of Engineering: Urbana, IL, USA, 1965.

31. EN 197-1, Cement Part 1: Composition, Specifications and Conformity Criteria for Common Cements, Br. Stand. 2011. Available online: https://doi.org/10.1103/PhysRevLett.64.88 (accessed on 18 December 2019).

32. Alfa, C. Ficha técnica EN 197-1 CEM IV/B (V) 32,5 N. in press.

33. Test Methods of Cements. Physical Analysis. Actual Density Determination, U.N.E. 80103:2013. 2013. Available online: https://infostore.saiglobal.com/en-us/Standards/UNE-80103-2013-22841_SAIG_AENOR_ AENOR_50269/ (accessed on 18 December 2019).

34. Methods of Testing Cement-Part 6: Determination of Fineness, E.N. 196-6:2010. 2010. Available online: https://webstore.ansi.org/standards/din/dinen1962010 (accessed on 18 December 2019).

35. Sainz-Aja, J.; Carrascal, I.; Polanco, J.A.; Thomas, C.; Sosa, I.; Casado, J.; Diego, S. Self-compacting recycled aggregate concrete using out-of-service railway superstructure wastes. J. Clean. Prod. 2019, 4, 386. [CrossRef]

36. Testing Hardened Concrete-Part 3: Compressive Strength of Test Specimens, U.-E. 12390-3:2009. 2009. Available online: https://www.scirp.org/(S(vtj3fa45qm1ean45vvffcz55))/reference/ReferencesPapers.aspx? ReferenceID=1884402 (accessed on 18 December 2019).

37. Testing Hardened Concrete—Part 3: Compressive Strength of Test Specimens, E.N. 12390-3:2099/AC:2011. 2011.

38. Testing Hardened Concrete-Part 13: Determination of Secant Modulus of Elasticity in Compression, E.N. 12390-13:2013. 2014. Available online: http://78.100.132.106/External\%20Documents/Intenational\%20Specifications/ British\%20Standards/BS\%20EN/BS\%20EN\%2012390-13-2013.pdf (accessed on 18 December 2019).

39. Locati, L. La Fatica dei Materiali Metallici; Ulrico Hoepli: Milan, Italy, 1950.

40. Locati, L. Programmed fatigue test, variable amplitude rotat. Metall. Ital. 1952, 44, 135-144. 
41. García, C.T. Hormigón Reciclado de Aplicación Estructural; Universidad de Cantabria: Santander, Spain, 2012. 42. Thomas, C.; Carrascal, I.; Setién, J.; Polanco, J.A. Determinación del límite a fatiga en hormigones reciclados de aplicación estructural-Determining the fatigue limit recycled concrete structural application. An. Mec. Fract. 2009, 1, 283-289. (In Spanish)

(C) 2019 by the authors. Licensee MDPI, Basel, Switzerland. This article is an open access article distributed under the terms and conditions of the Creative Commons Attribution (CC BY) license (http://creativecommons.org/licenses/by/4.0/). 